\title{
The effect of trans-10, cis-12 conjugated linoleic acid on gene expression profiles related to lipid metabolism in human intestinal-like Caco-2 cells
}

\author{
Eileen F. Murphy · Guido J. Hooiveld • \\ Michael Müller · Raffaelle A. Calogero • \\ Kevin D. Cashman
}

Received: 6 November 2008/Accepted: 16 February 2009/Published online: 13 March 2009

(c) Springer-Verlag 2009

\begin{abstract}
We conducted an in-depth investigation of the effects of conjugated linoleic acid (CLA) on the expression of key metabolic genes and genes of known importance in intestinal lipid metabolism using the Caco-2 cell model. Cells were treated with $80 \mu \mathrm{mol} / \mathrm{L}$ of linoleic acid (control), trans-10, cis-12 CLA or cis-9, trans-11 CLA. RNA was isolated from the cells, labelled and hybridized to the Affymetrix U133 2.0 Plus arrays $(n=3)$. Data and functional analysis were preformed using Bioconductor. Gene ontology analysis (GO) revealed a significant enrichment $(P<0.0001)$ for the GO term lipid metabolism with genes up-regulated by trans-10, cis-12 CLA. Trans-10, cis-12 CLA, but not cis-9, trans-11 CLA, altered the expression of a number of genes involved in lipid transport, fatty acid
\end{abstract}

This research was part funded by Safefood-The Food Safety Promotion Board, Ireland and by the EU-funded European Nutrigenomics Organisation (NuGO) Network of Excellence.

E. F. Murphy · K. D. Cashman ( $\square)$

Department of Food and Nutritional Sciences,

University College Cork, Cork, Ireland

e-mail: k.cashman@ucc.ie

E. F. Murphy

e-mail: Eileen.Murphy@ucc.ie

K. D. Cashman

Department of Medicine, University College Cork, Cork, Ireland

G. J. Hooiveld · M. Müller

Nutrition, Metabolism and Genomics Group,

Division of Human Nutrition, Wageningen University,

PO Box 8129, 6700EV

Wageningen, The Netherlands

R. A. Calogero

Bioinformatics and Genomics Unit, Department of Clinical and Biological Sciences, University of Turin, Orbassano, Italy metabolism, lipolysis, $\beta$-oxidation, steroid metabolism, cholesterol biosynthesis, membrane lipid metabolism, gluconeogenesis and the citrate cycle. These observations warrant further investigation to understand their potential role in the metabolic syndrome.

Keywords Conjugated linoleic acid · Gene expression · Caco-2 cells

\section{Introduction}

Conjugated linoleic acid (CLA) has been shown to have profound effects on hepatic and adipocyte lipid metabolism in both animal and cell models (see review by House et al. [22]). For example, it has been shown that CLA inhibits lipid accumulation [16] and alters lipid droplet morphology [7] in adipocytes. Several studies have examined the effects of CLA on apolipoprotein B-containing lipoproteins in hepatocytes [38, 51, 65]. Storkson et al. [51] demonstrated that while trans-10, cis-12 CLA decreased apolipoprotein secretion by Hep-G2 cells, the cis-9, trans-11 CLA isomer had no effect. These findings may be of therapeutic potential in relation to the metabolic syndrome, in which obesity, insulin resistance and hyperlipidemia are common characteristics $[17,18]$.

While the effects of CLA on lipid metabolism in hepatocytes and adipocytes have been well researched, its effect on intestinal lipid metabolism has been relatively overlooked. The intestine is of major importance in the digestion and absorption of dietary lipids, as well as in the re-synthesis and packaging of lipid for transport. As the site of absorption for dietary cholesterol, the intestine, together with the liver, serves an important regulatory role in the control of cholesterol homeostasis and plasma cholesterol 
levels [30]. Furthermore, recent work has demonstrated that the intestine contributes significantly to plasma high density lipoprotein (HDL) cholesterol levels [5]. Low HDL levels is an independent risk factor for the development of cardiovascular disease (CVD) [15].

Intestinal epithelial cells, as the first interface with dietary CLA, are exposed to the highest concentration of CLA isomers in vivo. Black et al. [4] showed that chronic supplementation of human intestinal-like Caco-2 cells with trans-10, cis-12 CLA, but not the cis-9, trans-11 isomer, modulated intestinal triacylglycerol (TAG) metabolism, by increasing cellular de novo TAG synthesis. However, CLA supplementation had no effect on TAG secretion from these intestinal-like cells [4]. The authors suggest that these results might imply that chronic supplementation with the trans-10, cis-12 CLA isomer may delay the secretion of TAG from the intestinal cell and contribute to reduced plasma TAG levels, thus potentially attenuating the postprandial TAG response. Elevated plasma TAG levels are associated with adverse effects on lipoprotein metabolism [48] and increased risk of CVD [59]. Roche and colleagues $[2,22]$ showed that supplementation with a mixed isomer CLA reduced fasting plasma TAG in healthy adults. However, the findings from other human studies are mixed (see review by Tricon and Yaqoob 57). The mechanisms by which CLA may influence TAG-rich lipoprotein metabolism in intestinal cells are unclear.

In our previous study, global gene expression analysis showed that chronic supplementation of Caco- 2 cells with the trans-10, cis-12 CLA isomer had profound effects on gene expression, whereas the cis-9, trans-11 isomer (the most abundant natural isomer) had no effect [41]. While particular emphasis was given to gene expression patterns of relevance to carcinogenesis and calcium transport, for which functional data exists, a number of wide-ranging biological processes of relevance to the intestine were modulated by trans-10, cis-12 CLA [41]. In particular, genes related to the process of lipid metabolism were found to be significantly altered. Thus, in this study we performed a more in-depth investigation of the effect of trans-10, cis12 CLA on gene expression profiles related to lipid metabolism, with a view to increasing our understanding of the role of the intestine in contributing to the effects of CLA on body composition, blood lipid profiles and glucose metabolism in human subjects.

\section{Materials and methods}

Conditions of cell culture and cell treatments

Caco-2 cells, a human colon adenocarcinoma cell line, were grown under routine conditions as described in the study by Jewell and Cashman [24]. Cells were seeded at a density of $6 \times 10^{4} \mathrm{~cm}^{-2}$ into six-well plastic cell culture plates (Costar) and and were treated with foetal bovine serum (FBS; 10\%) for 2 days and thereafter with FBS plus $80-\mu \mathrm{M}$ linoleic acid (as the control and parent fatty acid), $80-\mu \mathrm{M}$ trans-10, cis-12 isomer of CLA or $80-\mu \mathrm{M}$ cis-9, trans-11 isomer of CLA (as the non-esterified forms of the fatty acids) for a further 12 days, after initial seeding of the cells. The concentration of CLA $(80 \mu \mathrm{M})$ was chosen on the basis of the earlier estimate of typical luminal concentrations in the human small intestine of an individual with a daily dietary CLA intake of about $150 \mathrm{mg}$ [32]. All compounds were added to complete culture medium prior to their addition to the cells. The choice of collecting RNA at day 14 was on the basis that we have previously shown that our Caco- 2 cells are fully differentiated intestinal-like cells (as evidenced by brush border marker enzyme levels and transepithelial electrical resistance [24]).

RNA isolation, processing and microarray analysis

After experimental treatments, total RNA was extracted from the Caco-2 cells using TriReagent according to the manufacturer's directions (Molecular Research Center, Cincinnati, OH, USA) followed by an additional RNA purification step using the Rneasy mini kit (Qiagen Ltd, Crowley, West Sussex, UK). Total RNA was quantified and inspected using the Bioanalyzer 2100 (Agilent Technologies, Palo Alto, CA, USA). Starting from $1 \mu \mathrm{g}$ of total RNA for each sample, cDNA was synthesized using the one cycle cDNA synthesis kit (Affymetrix, USA) and biotinylated cRNA was generated by in vitro transcription, according to Affymetrix protocols (http://www.affymetrix.com/-support/ technical/manual/expression_manual.affx). Biotinylated cRNA was fragmented and each sample was hybridized to an Affymetrix HU133 2.0 Plus array $\left(54,645\right.$ probe sets) at $42^{\circ} \mathrm{C}$ for $17 \mathrm{~h}$, then washed, stained and scanned to generate digitized image data (DAT) files following the standard Affymetrix protocol.

\section{Microarray data analysis}

Three biological replicas were generated for each experimental condition (namely, $80-\mu \mathrm{M}$ linoleic acid, $80-\mu \mathrm{M}$ trans10, cis-12 CLA and 80- $\mu \mathrm{M}$ cis-9, trans-11 CLA). Microarray quality control and statistical validation were performed using Bioconductor [14]. A more detailed [22] description of the statistical analysis performed has been described elsewhere [41]. The list of differentially expressed genes was generated using a false discovery rate of 0.05 together with an absolute fold-change (fc) threshold of 1.6 (i.e. $|\log 2(\mathrm{fc})| \geq 0.7)$ and further refined by selecting those probe sets mapping to unique Entrez Gene identifiers (EGs) [35]. 
Gene ontology: functional enrichment analysis

Gene ontology (GO) provides a restricted vocabulary as well as clear indications of the relationships between biological terms and genes [1]. The up- and down-regulated differentially expressed genes were categorized according to two independent ontologies for gene products; (1) biological process and (2) molecular function, using EASE, in order to identify GO terms enriched [20].

\section{Results}

Global gene expression profile in CLA-treated cells

To profile the effects of the CLA isomers on gene expression in Caco-2 cells, the HU133 2.0 Plus array $(54,645$ probe sets), which provides the most comprehensive analysis of the transcribed human genome, was used. Of the 54,645 probe sets on the HU133 2.0 Plus array, 6,417 (11\%) were found to remain after applying the IQR filter of 0.3 . Linear model analysis indicated that the number of probe sets with apparently altered expression from Caco-2 cells treated with the cis-9, trans-11 CLA relative to linoleic acid (the parent and control fatty acid) was less than expected by random chance. Conversely, using a minimum fc criterion of 1.6 and a false discovery rate criterion of $P$ value 0.05 , 1,417 probe sets were found to be differentially expressed in Caco-2 cells treated with the trans-10, cis-12 CLA versus linoleic acid. Further refinement by grading scale (i.e. grade A) developed by Affymetrix (http://www.affymetrix.com) and for probe sets mapping to unique EGs showed that 918 EGs, were regulated by trans-10, cis-12 CLA treatment relative to linoleic acid. Among these EGs, 406 (44.2\%) were up-regulated and 512 (55.8\%) were down-regulated. We have previously validated the microarray data by confirming the altered expression of seven key genes using quantitative RT-PCR [41].

\section{Effect of trans-10, cis-12 CLA}

on lipid metabolism-related gene expression

In order to investigate the global effects of trans-10, cis-12 CLA on gut cell biology, the differentially expressed genes were partitioned into those up- and down-regulated by the trans-10, cis-12 CLA isomer and assessed for statistical enrichment by means of hypergeometric distribution of GO biological process and molecular function categories, as described in detail previously [41]. Of the various biological processes, a significant enrichment $(P<0.0001)$ for genes up-regulated by the trans-10, cis-12 CLA isomer was identified for the GO term lipid metabolism (GO: 0006629).
A number of genes encoding proteins which are involved in mediating lipid and cholesterol transport in the intestine were found to be either significantly up-regulated: fatty acid binding protein (FABP)-1 (2.04-fold) and FABP6 (2.94-fold); apolipoprotein A-IV (APOAIV) (6.98-fold) or down-regulated: ATP-binding cassette, sub-family A, member 1 (ABCA1) (4.63-fold) and apolipoprotein B mRNA editing enzyme (APOBEC1) (1.76-fold) in Caco-2 cells treated with trans-10, cis-12 CLA compared to linoleic acid-treated cells. Furthermore, the trans-10, cis-12 CLA down-regulated the expression of glycerol-3-phosphate acyltransferase (GPAT) (1.63-fold), the rate-limiting enzyme involved in fatty acid esterification (glycerol 3-phosphate pathway) in Caco-2 cells (Fig. 1).

Gene expression of a number of other rate-limiting enzymes in lipid metabolism-related pathways were also up-regulated by the trans-10, cis-12 CLA including: $\beta$ oxidation [carnitine palmitoyltransferase 1A (CPT1A) (2.81-fold)] and fatty acid metabolism [delta-9-desaturase (SCD) (2.14-fold)] (Table 1). Furthermore, the molecular expression of a number of key enzymes involved in the gluconeogenic/glycolysis pathway were significantly upregulated by trans-10, cis-12 CLA including: phosphoenol carboxylase kinase 1 (PCK1) (3.33-fold), the major control point for the regulation of gluconeogenesis; hexokinase 2 (HK2) (1.84-fold); aldolase B, fructose-bisbiphosphate (ALDOB) (3.67-fold) and fructose-1,6-bisphosphosphatase (FBP1) (2.00-fold). These findings suggest an effect of this isomer on glucose metabolism in Caco-2 cells (Table 1).

In relation to the various molecular functions modulated by the trans-10, cis-12 CLA isomer, the ligand-dependent nuclear receptor activity function (GO: 0004879) was found to be significantly enriched $(P<0.0001)$ by genes up-regulated by the trans-10, cis-12 CLA isomer of which 7 of the 52 ligand-dependent nuclear receptor activityassociated genes were found to be up-regulated. A number of these transcription factors are involved in mediating the effects of fatty acids on gene transcription including: peroxisome proliferator activated receptor gamma (PPAR $\gamma$ ) (2.82-fold); peroxisome proliferator activated receptor delta $(\operatorname{PPAR} \delta)$ (1.79-fold); hepatocyte nuclear factor 4, alpha (HNF4A) (2.23-fold) and farnesoid X receptor (FXR) (5.25-fold), all of which are up-regulated by the trans-10, cis-12 CLA isomer (Table 1).

\section{Discussion}

Adipose tissue, the liver and the intestine are key organs involved in lipid metabolism. In vitro and in vivo studies have shown that CLA affects lipid metabolism in adipocytes and hepatocytes (see reviews by House et al. [22] and Pariza et al. [43]). While the intestine is an important 


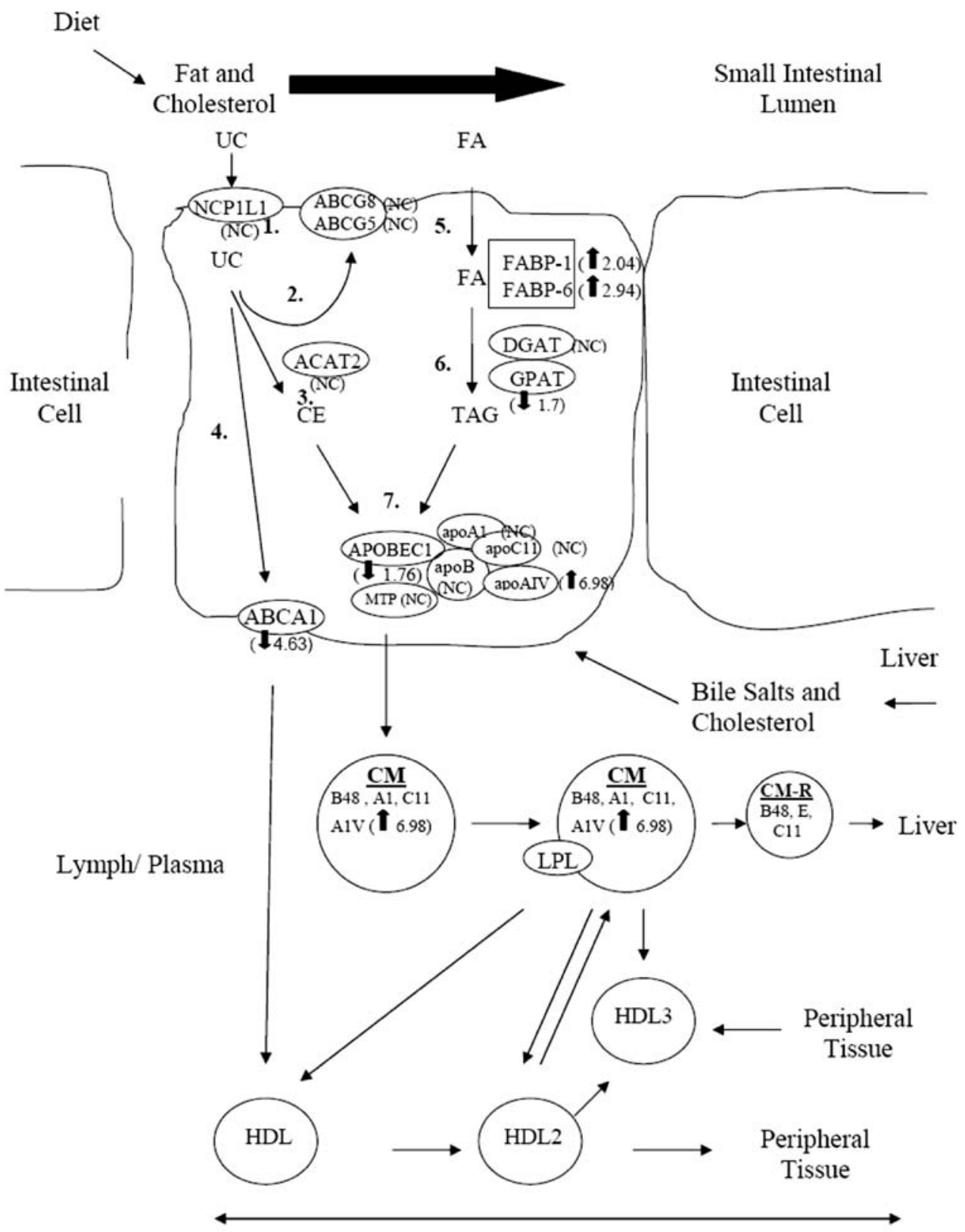

8.

Fig. 1 Changes in the expression of genes encoding mediators of lipid transport in Caco-2 cells treated with $80-\mu \mathrm{M}$ trans-10, cis-12 CLA relative to $80-\mu \mathrm{M}$ linoleic acid-treated cells. Up arrow and down arrow indicate up or down-regulation of transcription, fold-change (as determined by microarray analysis) is indicated in brackets and $N C$ no change. Processes represented include: 1 absorption of unesterified cholesterol (UC) mediated by the Niemann-Pick C1-like 1 (NPC1L1) protein, 2 expulsion of cholesterol (absorbed or synthesized locally in the enterocytes) into the intestinal lumen through the actions of the ATP-binding cassette $(A B C)$, subfamily G, member 5/ABCG8 heterodimeric transporter, 3 esterification of cholesterol $(C E)$ by acyl-coenzyme A: cholesterol acyltransferase 2 (ACAT2) for

source of plasma lipoproteins, second only to the liver [23], as well as having a primary role in the absorption and transport of dietary lipids, the effect of CLA on intestinal incorporation into chylomicrons $(C M), 4$ cholesterol transfer to plasma high density lipoproteins $(H D L)$ mediated by ABCA1, 5 fatty acids $(F A)$ absorption and transport of FA by fatty acid binding proteins $(F A B P)-1$ and FABP-6 to the endoplasmic reticulum for incorporation into triglyceride $(T A G)$ and phospholipids, 6 TAG synthesis pathways: rate-limiting enzymes in the monoacylglycerol and glycerol 3-phosphate pathways, respectively, are diacylglycerol acyltransferase $(D G A T)$ and glycerol-3-phosphate acyltransferase (GPAT), 7 chylomicron assembly and secretion, 8 transfer of proteins and lipid subfractions between $\mathrm{CM}$ and plasma lipoproteins (i.e. HDL). Apolipoprotein (apo), apoB mRNA editing enzyme (APO$B E C 1)$, microsomal triglyceride transfer protein (MTP)

lipid metabolism has not received much attention. Black et al. [4] showed that trans-10, cis-12 CLA, and not cis-9, trans-11 CLA, altered lipid metabolism in Caco-2 cells, 
Table 1 Genes regulated by trans-10, cis-12 CLA involved in lipid and glucose metabolism

Gene title

Gene symbol Entrez gene Fold change

\section{Lipid transport/storage}

Apolipoprotein A-IV

Fatty acid binding protein 6, ileal (gastrotropin)

Fatty acid binding protein 1 , liver

Low density lipoprotein receptor (familial hypercholesterolemia)

Apolipoprotein B mRNA editing enzyme, catalytic polypeptide 1

Solute carrier family 27 (fatty acid transporter), member 3

Apolipoprotein D

ATP-binding cassette, sub-family A (ABC1), member 1

\section{Lipolysis}

Monoglyceride lipase

Lipase, endothelial

Lipase, hepatic

\section{Fatty acid metabolism}

Stearoyl-CoA desaturase (delta-9-desaturase)

Acyl-CoA synthetase long-chain family member 1

Acyl-CoA synthetase long-chain family member 4

Thioesterase, adipose associated

Brain acyl-CoA hydrolase

Stearoyl-CoA desaturase 5

LAG1 longevity assurance homologue 6 (S. cerevisiae)

Fatty acid $\boldsymbol{\beta}$-oxidation

Carnitine palmitoyltransferase 1A (liver)

$\begin{array}{lrr}\text { APOA4 } & 337 & 6.98 \\ \text { FABP6 } & 2172 & 2.94 \\ \text { FABP1 } & 2168 & 2.04 \\ \text { LDLR } & 3948 & 1.72 \\ \text { APOBEC1 } & 9582 & -1.76 \\ \text { SLC27A3 } & 11000 & -1.76 \\ \text { APOD } & 347 & -3.32 \\ \text { ABCA1 } & 19 & -4.63 \\ & & \\ \text { MGLL } & 11343 & 2.22 \\ \text { LIPG } & 9388 & 1.65 \\ \text { LIPC } & 390 & -2.09 \\ & & \\ \text { SCD } & 6319 & 2.14 \\ \text { ACSL1 } & 2180 & 2.00 \\ \text { ACSL4 } & 2182 & 1.65 \\ \text { THEA } & 26027 & 1.65 \\ \text { BACH } & 11332 & -1.66 \\ \text { SCD5 } & 79966 & -2.77 \\ \text { LASS6 } & 253782 & -1.67 \\ & & \\ & & \end{array}$

\section{Steroid metabolism}

Hydroxysteroid (17-beta) dehydrogenase 2

Sulfotransferase family, cytosolic, 1B, member 1

Cytochrome P450, family 3, subfamily A, polypeptide 5

Sulfotransferase family, cytosolic, 1A, phenol-preferring, member 1

Sulfotransferase family, cytosolic, 1A, phenol-preferring, member 2

Sulfotransferase family, cytosolic, 1A, phenol-preferring, member 3

Dehydrogenase/reductase (SDR family) member 9

Lanosterol synthase (2,3-oxidosqualene-lanosterol cyclase)

Steroid sulfatase (microsomal), arylsulfatase $\mathrm{C}$, isozyme $\mathrm{S}$

Sulfotransferase family, cytosolic, 2A, dehydroepiandrosterone (DHEA)-preferring, member 1

UDP glycosyltransferase 2 family, polypeptide B17

\section{Cholesterol biosynthesis}

Protein kinase, AMP-activated, gamma 2 non-catalytic subunit

Mevalonate (diphospho) decarboxylase

7-Dehydrocholesterol reductase

CPT1A

1374

2.81

HSD17B2

SULT1B1

27284

3.06

CYP3A5

1577

2.07

SULT1A1

6817

1.97

SULT1A2

6799

1.88

SULT1A3

6818

1.83

DHRS9

10170

1.80

LSS

4047

1.73

STS

412

$-1.95$

SULT2A1

6822

$-1.98$

UGT2B17

7367

$-4.87$

PRKAG2 51322

2.33

MVD

DHCR7

1717

1.66

\section{Membrane lipid metabolism}

Annexin A1

Lysophosphatidylglycerol acyltransferase 1

Sphingomyelin phosphodiesterase 3, neutral membrane (neutral sphingomyelinase II)

Phospholipase D1, phosphatidylcholine-specific

$\begin{array}{lrr}\text { ANXA1 } & 301 & 2.78 \\ \text { LPGAT1 } & 9926 & 2.37 \\ \text { SMPD3 } & 55512 & 2.25 \\ \text { PLD1 } & 2822 & 1.81 \\ \text { SGPL1 } & 8879 & 1.79 \\ \text { PLAA } & 9373 & 1.77 \\ \text { MGC26963 } & 166929 & 1.66 \\ \text { SELI } & 85465 & 1.64\end{array}$

Phospholipase A2-activating protein

Hypothetical protein MGC26963

Selenoprotein I

6.98

.94

.04

.72
.14 .00 .65

65

.77


Table 1 continued

\begin{tabular}{|c|c|c|c|}
\hline Gene title & Gene symbol & Entrez gene & Fold change \\
\hline Glycerol-3-phosphate acyltransferase, mitochondrial & GPAM & 57678 & -1.63 \\
\hline Phosphatidic acid phosphatase type $2 \mathrm{~B}$ & PPAP2B & 8613 & -1.78 \\
\hline GM2 ganglioside activator & GM2A & 2760 & -1.83 \\
\hline \multicolumn{4}{|l|}{ Adipocyte secretory products } \\
\hline Adiponutrin & ADPN & 80339 & 1.66 \\
\hline Lipin 1 & LPIN1 & 23175 & 2.08 \\
\hline Adipose differentiation- related protein & ADFP & 123 & 1.75 \\
\hline \multicolumn{4}{|l|}{ Glycolysis and gluconeogenesis } \\
\hline Phosphofructokinase, platelet & PFKP & 5214 & 1.69 \\
\hline Fructose-1,6-bisphosphatase 1 & FBP1 & 2203 & 2.00 \\
\hline Aldolase B, fructose-bisphosphate & ALDOB & 229 & 3.67 \\
\hline Hexokinase 2 & HK2 & 3099 & 1.84 \\
\hline \multicolumn{4}{|l|}{ Citrate cycle } \\
\hline ATP citrate lyase & ACLY & 47 & 1.65 \\
\hline Isocitrate dehydrogenase 2 (NADP + ), mitochondrial & IDH2 & 3418 & -1.66 \\
\hline Phosphoenolpyruvate carboxykinase 1 (soluble) & PCK1 & 5105 & 3.33 \\
\hline \multicolumn{4}{|l|}{ Transcription factors } \\
\hline Nuclear receptor subfamily 1 , group $\mathrm{H}$, member 4 (farnesoid $\mathrm{X}$ receptor) & NR1H4 & 9971 & 5.25 \\
\hline Peroxisome proliferative activated receptor, gamma & PPARG & 5468 & 2.82 \\
\hline Hepatocyte nuclear factor 4 , alpha & HNF4A & 3172 & 2.23 \\
\hline Nuclear receptor subfamily 1 , group I, member 2 (Pregnane $X$ receptor) & NR1I2 & 8856 & 1.86 \\
\hline Peroxisome proliferative activated receptor, delta & PPARD & 5467 & 1.79 \\
\hline Nuclear receptor subfamily 2 , group F, member 2 (COUP-transcription factor 2) & $\mathrm{NR} 2 \mathrm{~F} 2$ & 7026 & -3.08 \\
\hline
\end{tabular}

which have been well characterized as a model for intestinal lipid metabolism [37, 50]. However, the mechanisms by which these isomer-specific effects of CLA are mediated on lipid metabolism in enterocytes are unclear. Thus, we conducted a more in-depth investigation of the isomerspecific effects of CLA on key metabolic genes and on genes of known importance in intestinal lipid metabolism.

In the present study, treatment of Caco-2 cells with trans10, cis-12 CLA altered the expression of a number of genes involved in lipid transport, fatty acid metabolism, lipolysis, $\beta$-oxidation, steroid metabolism, cholesterol biosynthesis, membrane lipid metabolism, gluconeogenesis and the citrate cycle, whereas cis-9, trans-11 CLA had no effect. While some of these effects have been reported in hepatic [8] and adipose tissue [21, 31], this is the first time, to our knowledge, that these effects have been reported in intestinal cells. In addition to providing new avenues of investigation, some of these molecular changes may underpin the observed cellular effects of trans-10, cis-12 CLA on intestinal lipid metabolism and its physiological correlates.

For example, Black et al. [4] showed that chronic treatment of Caco-2 cells with trans-10, cis-12 CLA increased de novo TAG synthesis but not TAG secretion or phospholipids synthesis and secretion. In the present study, the molecular expression of two important intracellular fatty acid binding proteins (FABP-1 and FABP-6) was up-regulated (2.04- and 2.94-fold, respectively) in Caco-2 cells by treatment with trans-10, cis-12 CLA. These lipid binding proteins mediate the transport of long-chain fatty acids to the endoplasmic reticulum for incorporation into TAG, cholesteryl esters and phospholipids [42, 52]. In addition, two major pathways, the monoacylglycerol and the glycerol 3-phosphate pathway, ensure fatty acid incorporation into TAG in the intestine. While the monoacylglycerol pathway is the primary one responsible for fatty acid esterification in the enterocyte, it is inactive in Caco- 2 cells $[34,50]$. In the present study, GPAT, the ratelimiting step in the glycerol 3-phosphate pathway was down-regulated (1.63-fold) in Caco-2 cells by treatment with trans-10, cis-12 CLA. ApoB mRNA editing enzyme (APOBEC1), which mediates the post-transcriptional editing of apoB-100 mRNA to apoB-48, was also downregulated (1.76-fold) in cells treated with trans-10, cis-12 CLA. Apo-48 is only synthesized in the intestine and is essential for the assembly of chylomicrons [23]. A decrease in expression of APOBEC1 would suggest an alteration in the ratio of apo-B48 to apoB-100. However, Black et al. [4] showed that chronic supplementation of Caco-2 cells with 
trans-10, cis-12 CLA (for 19 days) did not affect cellular apoB-48:apoB-100 levels.

The saturated fatty acid (SFA) to monounsaturated fatty acid (MUFA) ratio affects membrane phospholipid composition and alteration in this ratio has been implicated in a variety of disease states including CVD, obesity and diabetes [9]. Studies have shown that trans-10, cis-12 CLA, and not cis-9, trans-11 CLA, decreased stearyl-CoA desaturase (SCD1) activity and mRNA levels in hepatocytes [64] and SCD1 mRNA expression in adipocytes [6]. SCD1 is the rate-limiting enzyme in the conversion of SFA into MUFA, the major components of TAG and membrane phospholipids. At the cellular level CLA, in particular the trans-10, cis-12 CLA isomer, has been shown to increase the ratio of SFA to MUFA in adipocytes [6] and hepatocytes [11]. In the present study, SCD1 was up-regulated (2.14-fold) which would suggest a decrease in SFA:MUFA. However, the exact role of this enzyme and the effect of CLA on fatty acid profiles in the intestine are unclear.

Two important genes involved in intestinal lipid metabolism, which have a role in the regulation of blood lipid concentrations and potentially the development of atherosclerosis, were altered in Caco- 2 cells treated with trans-10, cis-12 CLA. Firstly, apoA-IV, a glycoprotein associated with TAG-rich chylomicrons and HDL [61] and primarily synthesized by the intestine [12] was up-regulated (6.98-fold). A protective role for apoA-IV in atherosclerosis has been demonstrated in animal studies $[10,60]$ and this protective role is further supported by the observation of an inverse relationship of apoA-IV levels and risk of CHD in human subjects [59, 63]. Interestingly, apoA-IV has also been suggested to play a role in the regulation of food intake by acting as a satiety factor [29, 45, 50]. Secondly, adenosine triphosphate-binding cassette protein A1 (ABCA1), a key mediator of cholesterol transport, was down-regulated (4.63-fold) in Caco-2 cells treated with trans-10, cis-12 CLA. It is postulated that intestinal ABCA1 is critical for nascent HDL formation in the intestine [39] and acts by directly mediating cholesterol transfer towards plasma HDL. Deletion of intestinal ABCA1 has been shown to result in a significant reduction $(30 \%)$ in plasma HDL in targeted knock-out mice [5], suggesting that a down-regulation of this protein by the trans-10, cis-12 CLA isomer may lead to a decrease in HDL-cholesterol derived from the intestine.

The up-regulation of intestinal apoA-IV by trans-10, cis-12 CLA may suggest a protective effect in relation to atherosclerosis, since HDL-particles enriched in apoA-1 and A-IV are considered anti-atherogenic [49, 50]. On the other hand, the down-regulation of intestinal ABCA1 may adversely affect HDL-cholesterol levels. Some, but not all, human studies have reported a reduction in plasma HDL- cholesterol levels following supplementation with mixed isomers of CLA (for review, see 56). Furthermore, this reduction in HDL has mainly been attributed to the trans10, cis-12 CLA isomer $[47,55]$. In animal models, some studies have suggested that both isomers of CLA may have a potential beneficial effect on atherosclerosis development [28, 36]. However, other more recent studies have suggested that the CLA isomers have divergent effects on atherosclerosis development [8, 54, 62], whereby trans-10, cis-12 CLA and cis-9, trans-11 CLA may in fact promote and inhibit the development of atherosclerosis, respectively. Although, in the present study, treatment of Caco-2 cells with cis-9, trans-11 CLA had no effect on gene expression related to processes involved in lipid metabolism in the intestine, the findings of recent studies indicate that cis-9, trans-11 CLA may have effects on atherosclerosis development beyond the intestine. For example, cis-9, trans-11 CLA induced anti-inflammatory proteins in the liver [8] and may impart its anti-atherosclerotic effects by inducing apoptosis and negatively regulating the expression of pro-inflammatory genes in the atherosclerotic lesion $[54,58]$.

It has been suggested that CLA may impart its antiobesity effects by increasing $\beta$-oxidation in the liver [46, 53], adipose tissue [44, 46] and skeletal muscle [44]. Interestingly, in the present study treatment of Caco-2 cells with trans-10, cis-12 CLA lead to an up-regulation (2.81-fold) of CPT1A, a mitochondrial membrane bound protein that is essential for shuttling long-chain fatty acids into the mitochondria to undergo $\beta$-oxidation. Several studies have shown that CLA, in particular the trans-10, cis-12 CLA isomer, increased CPT1A mRNA levels in liver [8] and adipose tissue [22, 31] as well as CPT1A activity in adipose tissue [44, 46]. However, this is the first study, to our knowledge, to suggest that CLA increases CPT1A expression in the intestine. Murase et al. [40] showed that dietary diacylglycerol significantly suppresses body weight gain in mice, an effect which is accompanied by an up-regulation of genes involved in lipid metabolism resulting in a subsequent increase in $\beta$-oxidation in the small intestine. Thus, the trans-10, cis-12 CLA-mediated increase in CPT1A expression in the intestine may result in increased intestinal energy expenditure and contribute, at least in part, to the weight loss effects of trans-10, cis-12 CLA which have been demonstrated in several animal models [19, 21, 31, 44]. Further investigation is needed to determine the exact effect of CLA on $\beta$-oxidation in the intestine.

It has been suggested that CLA may mediate its effects through the peroxisome proliferator activated receptor (PPAR) transcription factors, which consist of three closely related gene products, $\operatorname{PPAR} \alpha,-\delta$ and $-\gamma$ [26, 31]. Interestingly, $\operatorname{PPAR} \delta$ and $-\gamma$ were found to be up-regulated 
(1.79- and 2.82-fold, respectively) in Caco-2 cells by treatment with the trans-10, cis-12 CLA isomer. These transcription factors play an important role in a wide range of biological processes including lipid and glucose metabolism in a variety of tissues and have been implicated in a number of disease pathologies such as obesity, atherosclerosis and diabetes [13, 25, 27]. A number of other nuclear receptors such as the hepatocyte nuclear factor 4 , alpha (HNF4A), the pregnane $\mathrm{X}$ receptor (NF1I2), the FXR and the COUP-transcription factor 2 (NR2F2) were also up-regulated by trans-10, cis-12 CLA. While these nuclear receptors offer potential as candidates to explain the CLAmediated changes in gene expression, further work is required to establish their exact role.

The present study had a number of potential limitations. The Caco- 2 cells were differentiated on plastic supports rather than on filter supports, the latter more typical in functional studies. Le Beyec et al. [33] have shown that expression of several genes involved in lipid metabolism in Caco-2 cells grown in plastic support was impaired compared to that observed when the cells were grown on filter supports. While the effect of apical exposure of the CLA isomers to intestinal cells was our primary interest, we acknowledge that exposure of Caco- 2 cells to isomers of CLA at the basolateral side (reflecting circulating levels) may induce different physiological responses within the intestinal-like cells. Beaslas et al. [3] have recently shown that the polarity (apical vs. basal pole) as well as the mode of lipid delivery (albumin-bound vs. lipid micelles) are important determinants of enterocyte gene expression in Caco-2 cells. These considerations would need to be addressed in further studies to better clarify the role of CLA on lipid metabolism.

In conclusion, the trans-10, cis-12 CLA induced alterations in the expression of genes involved in regulating the intestinal component of a number of processes including TAG metabolism, cholesterol transfer to HDL, gluconeogenesis and $\beta$-oxidation. These gene expression patterns suggest that trans-10, cis-12 CLA may have potential negative effects on intestinal HDL biogenesis and glucose metabolism while increasing $\beta$-oxidation and altering TAG metabolism in Caco- 2 cells. These observations supported by evidence in some animal and human studies warrant further investigation, including follow-up with functional studies.

\section{References}

1. Ashburner M, Ball CA, Blake JA, Botstein D, Butler H, Cherry JM, Davis AP, Dolinski K, Dwight SS, Eppig JT, Harris MA, Hill DP, Issel-Tarver L, Kasarskis A, Lewis S, Matese JC, Richardson JE, Ringwald M, Rubin GM, Sherlock G (2000) Gene ontology: tool for the unification of biology. The Gene Ontology Consortium. Nat Genet 25:25-29

2. Bassaganya-Riera J, Hontecillas R (2006) CLA and n-3 PUFA differentially modulate clinical activity and colonic PPARresponsive gene expression in a pig model of experimental IBD. Clin Nutr 25:454-465

3. Beaslas O, Torreilles F, Casellas P, Simon D, Fabre G, Lacasa M, Delers F, Chambaz J, Rousset M, Carriere V (2008) Transcriptome response of enterocytes to dietary lipids: impact on cell architecture, signaling, and metabolism genes. Am J Physiol Gastrointest Liver Physiol 295:G942-G952

4. Black IL, Roche HM, Gibney MJ (2002) Chronic but not acute treatment with conjugated linoleic acid (CLA) isomers (trans-10, cis-12 CLA and cis-9, trans-11 CLA) affects lipid metabolism in Caco-2 cells. J Nutr 132:2167-2173

5. Brunham LR, Kruit JK, Iqbal J, Fievet C, Timmins JM, Pape TD, Coburn BA, Bissada N, Staels B, Groen AK, Hussain MM, Parks JS, Kuipers F, Hayden MR (2006) Intestinal ABCA1 directly contributes to HDL biogenesis in vivo. J Clin Invest 116:10521062

6. Choi Y, Kim YC, Han YB, Park Y, Pariza MW, Ntambi JM (2000) The trans-10, cis-12 isomer of conjugated linoleic acid downregulates stearoyl-CoA desaturase 1 gene expression in 3T3-L1 adipocytes. J Nutr 130:1920-1924

7. Chung S, Brown JM, Provo JN, Hopkins R, McIntosh MK (2005) Conjugated linoleic acid promotes human adipocyte insulin resistance through NFkappaB-dependent cytokine production. $\mathbf{J}$ Biol Chem 280:38445-38456

8. de Roos B, Rucklidge G, Reid M, Ross K, Duncan G, Navarro MA, Arbones-Mainar JM, Guzman-Garcia MA, Osada J, Browne J, Loscher CE, Roche HM (2005) Divergent mechanisms of cis9, trans11- and trans10, cis12-conjugated linoleic acid affecting insulin resistance and inflammation in apolipoprotein E knockout mice: a proteomics approach. FASEB J 19:1746-1748

9. Dobrzyn A, Ntambi JM (2005) The role of stearoyl-CoA desaturase in the control of metabolism. Prostaglandins Leukot Essent Fatty Acids 73:35-41

10. Duverger N, Tremp G, Caillaud JM, Emmanuel F, Castro G, Fruchart JC, Steinmetz A, Denefle P (1996) Protection against atherogenesis in mice mediated by human apolipoprotein A-IV. Science 273:966-968

11. Eder K, Slomma N, Becker K (2002) Trans-10, cis-12 conjugated linoleic acid suppresses the desaturation of linoleic and alphalinolenic acids in HepG2 cells. J Nutr 132:1115-1121

12. Elshourbagy NA, Walker DW, Paik YK, Boguski MS, Freeman M, Gordon JI, Taylor JM (1987) Structure and expression of the human apolipoprotein A-IV gene. J Biol Chem 262:7973-7981

13. Evans RM, Barish GD, Wang YX (2004) PPARs and the complex journey to obesity. Nat Med 10:355-361

14. Gentleman RC, Carey VJ, Bates DM, Bolstad B, Dettling M, Dudoit S, Ellis B, Gautier L, Ge Y, Gentry J, Hornik K, Hothorn $\mathrm{T}$, Huber W, Iacus S, Irizarry R, Leisch F, Li C, Maechler M, Rossini AJ, Sawitzki G, Smith C, Smyth G, Tierney L, Yang JY, Zhang J (2004) Bioconductor: open software development for computational biology and bioinformatics. Genome Biol 5:R80

15. Gordon DJ, Probstfield JL, Garrison RJ, Neaton JD, Castelli WP, Knoke JD, Jacobs DR Jr, Bangdiwala S, Tyroler HA (1989) High-density lipoprotein cholesterol and cardiovascular disease. Four prospective American studies. Circulation 79:8-15

16. Granlund L, Pedersen JI, Nebb HI (2005) Impaired lipid accumulation by trans 10 , cis 12 CLA during adipocyte differentiation is dependent on timing and length of treatment. Biochim Biophys Acta 1687:11-22

17. Grundy SM, Cleeman JI, Daniels SR, Donato KA, Eckel RH, Franklin BA, Gordon DJ, Krauss RM, Savage PJ, Smith SC Jr, Spertus JA, Costa F (2006) Diagnosis and management of the 
metabolic syndrome: an American Heart Association/National Heart, Lung, and Blood Institute scientific statement. Curr Opin Cardiol 21:1-6

18. Haffner SM (2006) The metabolic syndrome: inflammation, diabetes mellitus, and cardiovascular disease. Am J Cardiol 97:3A-11A

19. Hargrave KM, Li C, Meyer BJ, Kachman SD, Hartzell DL, DellaFera MA, Miner JL, Baile CA (2002) Adipose depletion and apoptosis induced by trans-10, cis-12 conjugated linoleic acid in mice. Obes Res 10:1284-1290

20. Hosack DA, Dennis G Jr, Sherman BT, Lane HC, Lempicki RA (2003) Identifying biological themes within lists of genes with EASE. Genome Biol 4:R70

21. House RL, Cassady JP, Eisen EJ, Eling TE, Collins JB, Grissom SF, Odle J (2005) Functional genomic characterization of delipidation elicited by trans-10, cis-12-conjugated linoleic acid (t10c12-CLA) in a polygenic obese line of mice. Physiol Genomics 21:351-361

22. House RL, Cassady JP, Eisen EJ, McIntosh MK, Odle J (2005) Conjugated linoleic acid evokes de-lipidation through the regulation of genes controlling lipid metabolism in adipose and liver tissue. Obes Rev 6:247-258

23. Hussain MM, Fatma S, Pan X, Iqbal J (2005) Intestinal lipoprotein assembly. Curr Opin Lipidol 16:281-285

24. Jewell C, Cashman KD (2003) The effect of conjugated linoleic acid and medium-chain fatty acids on transepithelial calcium transport in human intestinal-like Caco-2 cells. Br J Nutr 89:639647

25. Kersten S, Desvergne B, Wahli W (2000) Roles of PPARs in health and disease. Nature 405:421-424

26. Khan SA, Vanden Heuvel JP (2003) Role of nuclear receptors in the regulation of gene expression by dietary fatty acids (review). J Nutr Biochem 14:554-567

27. Kota BP, Huang TH, Roufogalis BD (2005) An overview on biological mechanisms of PPARs. Pharmacol Res 51:85-94

28. Kritchevsky D, Tepper SA, Wright S, Czarnecki SK, Wilson TA, Nicolosi RJ (2004) Conjugated linoleic acid isomer effects in atherosclerosis: growth and regression of lesions. Lipids 39:611616

29. Kritchevsky D, Tepper SA, Wright S, Tso P, Czarnecki SK (2000) Influence of conjugated linoleic acid (CLA) on establishment and progression of atherosclerosis in rabbits. J Am Coll Nutr 19:472S-477S

30. Kruit JK, Groen AK, van Berkel TJ, Kuipers F (2006) Emerging roles of the intestine in control of cholesterol metabolism. World J Gastroenterol 12:6429-6439

31. LaRosa PC, Miner J, Xia Y, Zhou Y, Kachman S, Fromm ME (2006) Trans-10, cis-12 conjugated linoleic acid causes inflammation and delipidation of white adipose tissue in mice: a microarray and histological analysis. Physiol Genomics 27:282294

32. Lawson R, Moss A, Givens D (2001) The role of dairy products in supplying conjugated linoleic acid to man's diet: a review. Nutr Res Rev 14:153-172

33. Le Beyec J, Delers F, Jourdant F, Schreider C, Chambaz J, Cardot P, Pincon-Raymond M (1997) A complete epithelial organization of Caco-2 cells induces I-FABP and potentializes apolipoprotein gene expression. Exp Cell Res 236:311-320

34. Levy E, Mehran M, Seidman E (1995) Caco-2 cells as a model for intestinal lipoprotein synthesis and secretion. FASEB J 9:626635

35. Maglott D, Ostell J, Pruitt KD, Tatusova T (2005) Entrez gene: gene-centered information at NCBI. Nucleic Acids Res 33:D54D58

36. McLeod RS, LeBlanc AM, Langille MA, Mitchell PL, Currie DL (2004) Conjugated linoleic acids, atherosclerosis, and hepatic very-low-density lipoprotein metabolism. Am J Clin Nutr 79:1169S-1174S

37. Mehran M, Levy E, Bendayan M, Seidman E (1997) Lipid, apolipoprotein, and lipoprotein synthesis and secretion during cellular differentiation in Caco-2 cells. In Vitro Cell Dev Biol Anim 33:118-128

38. Mitmesser SH, Carr TP (2005) Trans fatty acids alter the lipid composition and size of apoB-100-containing lipoproteins secreted by HepG2 cells. J Nutr Biochem 16:178-183

39. Mulligan JD, Flowers MT, Tebon A, Bitgood JJ, Wellington C, Hayden MR, Attie AD (2003) ABCA1 is essential for efficient basolateral cholesterol efflux during the absorption of dietary cholesterol in chickens. J Biol Chem 278:13356-13366

40. Murase T, Aoki M, Wakisaka T, Hase T, Tokimitsu I (2002) Anti-obesity effect of dietary diacylglycerol in C57BL/6J mice: dietary diacylglycerol stimulates intestinal lipid metabolism. J Lipid Res 43:1312-1319

41. Murphy EF, Hooiveld GJ, Muller M, Calogero RA, Cashman KD (2007) Conjugated linoleic acid alters global gene expression in human intestinal-like Caco-2 cells in an isomer-specific manner. J Nutr 137:2359-2365

42. Ockner RK, Manning JA (1974) Fatty acid-binding protein in small intestine. Identification, isolation, and evidence for its role in cellular fatty acid transport. J Clin Invest 54:326-338

43. Pariza MW, Park Y, Cook ME (2001) The biologically active isomers of conjugated linoleic acid. Prog Lipid Res 40:283-298

44. Park HS, Ryu JH, Ha YL, Park JH (2001) Dietary conjugated linoleic acid (CLA) induces apoptosis of colonic mucosa in 1, 2-dimethylhydrazine-treated rats: a possible mechanism of the anticarcinogenic effect by CLA. Br J Nutr 86:549-555

45. Qin X, Tso P (2005) The role of apolipoprotein AIV on the control of food intake. Curr Drug Targets 6:145-151

46. Rahman SM, Wang Y, Yotsumoto H, Cha J, Han S, Inoue S, Yanagita T (2001) Effects of conjugated linoleic acid on serum leptin concentration, body-fat accumulation, and beta-oxidation of fatty acid in OLETF rats. Nutrition 17:385-390

47. Riserus U, Arner P, Brismar K, Vessby B (2002) Treatment with dietary trans10cis12 conjugated linoleic acid causes isomerspecific insulin resistance in obese men with the metabolic syndrome. Diabetes Care 25:1516-1521

48. Roche HM, Gibney MJ (2000) Effect of long-chain n-3 polyunsaturated fatty acids on fasting and postprandial triacylglycerol metabolism. Am J Clin Nutr 71:232S-237S

49. Rubin EM, Krauss RM, Spangler EA, Verstuyft JG, Clift SM (1991) Inhibition of early atherogenesis in transgenic mice by human apolipoprotein AI. Nature 353:265-267

50. Stan S, Delvin E, Lambert M, Seidman E, Levy E (2003) Apo A-IV: an update on regulation and physiologic functions. Biochim Biophys Acta 1631:177-187

51. Storkson J, Park Y, Cook M, Pariza M (2005) Effects of trans-10, cis-12 conjugated linoleic acid and cognates on apolipoprotein B secretion in Hep G2 cells. Nutr Res 25:387-399

52. Sweetser DA, Lowe JB, Gordon JI (1986) The nucleotide sequence of the rat liver fatty acid-binding protein gene. Evidence that exon 1 encodes an oligopeptide domain shared by a family of proteins which bind hydrophobic ligands. J Biol Chem 261:55535561

53. Taparia S, Fleet JC, Peng JB, Wang XD, Wood RJ (2006) 1, 25-Dihydroxyvitamin D and 25-hydroxyvitamin D-mediated regulation of TRPV6 (a putative epithelial calcium channel) mRNA expression in Caco-2 cells. Eur J Nutr 45:196-204

54. Toomey S, Harhen B, Roche HM, Fitzgerald D, Belton O (2006) Profound resolution of early atherosclerosis with conjugated linoleic acid. Atherosclerosis 187:40-49

55. Tricon S, Burdge GC, Kew S, Banerjee T, Russell JJ, Jones EL, Grimble RF, Williams CM, Yaqoob P, Calder PC (2004) 
Opposing effects of cis-9, trans-11 and trans-10, cis-12 conjugated linoleic acid on blood lipids in healthy humans. Am J Clin Nutr 80:614-620

56. Tricon S, Burdge GC, Williams CM, Calder PC, Yaqoob P (2005) The effects of conjugated linoleic acid on human healthrelated outcomes. Proc Nutr Soc 64:171-182

57. Tricon S, Yaqoob P (2006) Conjugated linoleic acid and human health: a critical evaluation of the evidence. Curr Opin Clin Nutr Metab Care 9:105-110

58. Valeille K, Ferezou J, Amsler G, Quignard-Boulange A, Parquet M, Gripois D, Dorovska-Taran V, Martin JC (2005) A cis-9, trans-11-conjugated linoleic acid-rich oil reduces the outcome of atherogenic process in hyperlipidemic hamster. Am J Physiol Heart Circ Physiol 289:H652-H659

59. Weiler H, Austin S, Fitzpatrick-Wong S, Nitschmann E, Bankovic-Calic N, Mollard R, Aukema H, Ogborn M (2004) Conjugated linoleic acid reduces parathyroid hormone in health and in polycystic kidney disease in rats. Am J Clin Nutr 79: 1186S-1189S

60. Weinstock PH, Bisgaier CL, Hayek T, Aalto-Setala K, Sehayek E, Wu L, Sheiffele P, Merkel M, Essenburg AD, Breslow JL (1997) Decreased HDL cholesterol levels but normal lipid absorption, growth, and feeding behavior in apolipoprotein A-IV knockout mice. J Lipid Res 38:1782-1794
61. Weisgraber KH, Bersot TP, Mahley RW (1978) Isolation and characterization of an apoprotein from the d less than 1.006 lipoproteins of human and canine lymph homologous with the rat A-IV apoprotein. Biochem Biophys Res Commun 85:287-292

62. Wilson TA, Nicolosi RJ, Saati A, Kotyla T, Kritchevsky D (2006) Conjugated linoleic acid isomers reduce blood cholesterol levels but not aortic cholesterol accumulation in hypercholesterolemic hamsters. Lipids 41:41-48

63. Wong WM, Hawe E, Li LK, Miller GJ, Nicaud V, Pennacchio LA, Humphries SE, Talmud PJ (2003) Apolipoprotein AIV gene variant S347 is associated with increased risk of coronary heart disease and lower plasma apolipoprotein AIV levels. Circ Res 92:969-975

64. Wood RJ, Fleet JC, Cashman K, Bruns ME, Deluca HF (1998) Intestinal calcium absorption in the aged rat: evidence of intestinal resistance to $1,25(\mathrm{OH}) 2$ vitamin D. Endocrinology 139: 3843-3848

65. Zabala A, Churruca I, Macarulla MT, Rodriguez VM, FernandezQuintela A, Martinez JA, Portillo MP (2004) The trans-10, cis-12 isomer of conjugated linoleic acid reduces hepatic triacylglycerol content without affecting lipogenic enzymes in hamsters. Br J Nutr 92:383-389 